\title{
Astrocytes Regulate GLP-1 Receptor-Mediated Effects on Energy Balance
}

\author{
David J. Reiner, ${ }^{1 *}$ Elizabeth G. Mietlicki-Baase, ${ }^{1 *}$ Lauren E. McGrath, ${ }^{1}$ Derek J. Zimmer, ${ }^{1,2}$ Kendra K. Bence, ${ }^{2}$ \\ Gregory L. Sousa, ${ }^{1,2}$ Vaibhav R. Konanur, ${ }^{3}$ 'Joanna Krawczyk, ${ }^{1}$ David H. Burk, ${ }^{4}$ Scott E. Kanoski, ${ }^{3}$ \\ Q Gerlinda E. Hermann, ${ }^{4}$ Richard C. Rogers, ${ }^{4}$ and Matthew R. Hayes ${ }^{1}$ \\ ${ }^{1}$ Translational Neuroscience Program, Department of Psychiatry, Perelman School of Medicine, and 2Department of Animal Biology, School of Veterinary \\ Medicine, University of Pennsylvania, Philadelphia, Pennsylvania 19104, ${ }^{3}$ Department of Biological Sciences, Human and Evolutionary Biology Section, \\ University of Southern California, Los Angeles, California 90089, and ${ }^{4}$ Pennington Biomedical Research Center, Louisiana State University, Baton Rouge, \\ Louisiana 70808
}

Astrocytes are well established modulators of extracellular glutamate, but their direct influence on energy balance-relevant behaviors is largely understudied. As the anorectic effects of glucagon-like peptide-1 receptor (GLP-1R) agonists are partly mediated by central modulation of glutamatergic signaling, we tested the hypothesis that astrocytic GLP-1R signaling regulates energy balance in rats. Central or peripheral administration of a fluorophore-labeled GLP-1R agonist, exendin-4, localizes within astrocytes and neurons in the nucleus tractus solitarius (NTS), a hindbrain nucleus critical for energy balance control. This effect is mediated by GLP-1R, as the uptake of systemically administered fluorophore-tagged exendin- 4 was blocked by central pretreatment with the competitive GLP-1R antagonist exendin-(9-39). Ex vivo analyses show prolonged exendin-4-induced activation (live cell calcium signaling) of NTS astrocytes and neurons; these effects are also attenuated by exendin-(9-39), indicating mediation by the GLP-1R. In vitro analyses show that the application of GLP-1R agonists increases cAMP levels in astrocytes. Immunohistochemical analyses reveal that endogenous GLP-1 axons form close synaptic apposition with NTS astrocytes. Finally, pharmacological inhibition of NTS astrocytes attenuates the anorectic and body weight-suppressive effects of intra-NTS GLP-1R activation. Collectively, data demonstrate a role for NTS astrocytic GLP-1R signaling in energy balance control.

Key words: astrocyte; exendin-4; food intake; GLP-1; liraglutide; obesity

\section{Significance Statement}

Glucagon-like peptide-1 receptor (GLP-1R) agonists reduce food intake and are approved by the Food and Drug Administration for the treatment of obesity, but the cellular mechanisms underlying the anorectic effects of GLP-1 require further investigation. Astrocytes represent a major cellular population in the CNS that regulates neurotransmission, yet the role of astrocytes in mediating energy balance is largely unstudied. The current data provide novel evidence that astrocytes within the NTS are relevant for energy balance control by GLP-1 signaling. Here, we report that GLP-1R agonists activate and internalize within NTS astrocytes, while behavioral data suggest the pharmacological relevance of NTS astrocytic GLP-1R activation for food intake and body weight. These findings support a previously unknown role for CNS astrocytes in energy balance control by GLP-1 signaling.

\section{Introduction}

The nucleus tractus solitarius (NTS) of the caudal brainstem is a critical nucleus in the regulation of energy balance. The NTS acts as a sensor for circulating neuroendocrine factors important for the control of food intake and is the first nucleus within the brain to receive and process vagally mediated satiation signals arising 
from the gastrointestinal (GI) tract (Grill and Hayes, 2012). The NTS is therefore well positioned as a key hub to combine a variety of feeding-related signals, and to transmit this integrated information to downstream nuclei to influence overall energy balance control (Grill and Hayes, 2009). Within the NTS, the incretin hormone glucagon-like peptide-1 (GLP-1) acts to control food intake and body weight (Grill and Hayes, 2012; Hayes et al., 2014). Produced peripherally by intestinal L cells and centrally by preproglucagon (PPG) neurons within the caudal NTS, GLP-1 and GLP-1 receptor (GLP-1R) agonists suppress food intake and body weight through direct GLP-1R signaling in the NTS, as well as through action in other distributed nuclei in the brain (McMahon and Wellman, 1998; Grill and Hayes, 2009; Dossat et al., 2011; Alhadeff et al., 2012; Mietlicki-Baase et al., 2013, 2014; Rupprecht et al., 2013; Alhadeff et al., 2014; Secher et al., 2014; Hsu et al., 2015). However, the cellular and molecular mechanisms mediating the energy balance effects of GLP-1R activation remain largely underinvestigated. GLP-1R agonists such as exendin-4 (Ex-4) and liraglutide are widely used in the treatment of type 2 diabetes mellitus (T2DM; Hayes et al., 2014), and liraglutide was recently approved by the Food and Drug Administration (FDA) for the treatment of obesity (Tella and Rendell, 2015). These important medical applications of GLP-1R agonists highlight the urgent need to understand more fully the mechanisms by which GLP-1R activation impacts physiology and behavior, including the control of feeding and body weight.

Vagal afferents synapsing in the NTS, as well as NTS PPG neurons themselves, are glutamatergic (Ritter, 2004; Grill and Hayes, 2012; Zheng et al., 2015). Thus, recent attention has focused on the role of glutamatergic signaling in mediating the anorexigenic effects of central GLP-1R activation. In particular, several studies demonstrate a role for the ionotropic AMPA/kainate glutamate receptors (Hisadome et al., 2011; Mietlicki-Baase et al., 2013; Mietlicki-Baase et al., 2014) as downstream mediators of the food intake- and body weight-suppressive effects of GLP-1R signaling within midbrain and forebrain nuclei. Importantly, these reports also indicate that the relevant GLP-1Rs are located presynaptically to AMPA/kainate receptors and can influence presynaptic glutamate release (Acuna-Goycolea and van den Pol, 2004; Amato et al., 2010; Hisadome et al., 2011; Mietlicki-Baase et al., 2013,2014). However, to date, the ability of GLP-1R activation to affect energy balance via non-neuronal modulation of synaptic glutamatergic signaling has not been systematically evaluated.

Most studies of the central control of energy balance have focused on the actions of neurons, but astrocytes represent another key CNS cell population that modulates glutamatergic neurotransmission, thereby potentially influencing behavior (Scofield and Kalivas, 2014; Yang et al., 2015). Indeed, glutamate is predominately cleared from the synapse by the following two subtypes of astrocytic glutamate reuptake transporters: glutamate transporter-1 (GLT-1) and glutamate aspartate transporter (GLAST; Perego et al., 2000; Danbolt, 2001). Intriguingly, a small body of literature suggests that astrocytes within the CNS express the GLP-1R (Chowen et al., 1999; Iwai et al., 2006; Kobayashi et al., 2013), yet no studies have systemically examined its expression or behavioral relevance for energy balance control. As the NTS expresses GLP-1R (Hayes et al., 2010; Hayes, 2012) and is the first central site to receive and process within-meal vagally mediated glutamatergic signals arising from the GI tract (Moran, 2006; Grill and Hayes, 2009), a combination of in vitro, ex vivo, and in vivo techniques was used to test the hypothesis that
GLP-1R signaling in NTS astrocytes is functionally relevant for energy balance control.

\section{Materials and Methods}

Animals

Male Sprague Dawley rats (weight, 320-420 g; Charles River Laboratories) individually housed in hanging wire cages maintained at $23^{\circ} \mathrm{C}$ with a $12 \mathrm{~h}$ light/dark cycle were used for the majority of these studies. For the live cell calcium imaging studies, male Long-Evans rats (weight, 250-300 g; from a breeding colony at Pennington Biomedical Research Center) were used. All procedures were approved by Institutional Animal Care and Use Committees (at the University of Pennsylvania, the University of Southern California, and the Pennington Biomedical Research Center) and were performed according to the guidelines determined by the $\mathrm{Na}$ tional Institutes of Health. Rats had ad libitum access to rodent chow and water unless otherwise noted.

\section{Stereotaxic surgery}

For behavioral experiments, rats were surgically implanted with cannula targeting either the medial NTS (mNTS) or fourth cerebroventricle. Rats were anesthetized with an intramuscular injection of ketamine $(90 \mathrm{mg} /$ $\mathrm{kg})$, xylazine $(2.7 \mathrm{mg} / \mathrm{kg})$, and acepromazine $(0.64 \mathrm{mg} / \mathrm{kg})$, and placed in a stereotaxic apparatus. Guide cannulae (Plastics One; 26 gauge) were implanted using the following coordinates: fourth cerebroventricle (midline, $2.5 \mathrm{~mm}$ anterior to the occipital suture, internal cannula aimed $7.2 \mathrm{~mm}$ ventral to skull); and mNTS (bilateral cannula; $1.0 \mathrm{~mm}$ posterior to occipital crest, $\pm 0.5 \mathrm{~mm}$ lateral to midline, internal cannula aimed 8.7 $\mathrm{mm}$ ventral to skull). Bone screws and dental cement adhered the cannula to the skull surface. Animals were treated with analgesia $(2 \mathrm{mg} / \mathrm{kg}$ meloxicam, s.c.) and were allowed 1 week to recover. Behavioral testing began $\sim 14 \mathrm{~d}$ after surgery.

Fourth cerebroventricle cannula placements were verified before behavioral testing by assessing the hyperglycemic response to 5-thio-Dglucose $(210 \mu \mathrm{g})$, as described previously (Hayes et al., 2009). mNTS injection sites were confirmed anatomically following a postmortem injection of $100 \mathrm{nl}$ of pontamine sky blue. Only animals passing functional or histological verifications were included in the final statistical analysis.

\section{Immunohistochemical analyses}

Detection and cellular localization of fluorescently labeled Ex-4. Rats were injected with fluorophore-labeled Ex-4 (fluoro-Ex-4; AnaSpec) either in the fourth cerebroventricle $(0.3 \mu \mathrm{g} / 1 \mu \mathrm{l}$; maintained on chow ad libitum $)$ or intraperitoneally ( $10 \mu \mathrm{g} / \mathrm{ml} / \mathrm{kg}$; given ad libitum access to chow, vegetable shortening, and 30\% sucrose). This ligand has been shown to bind to GLP-1R in cultured GLP-1R-expressing pancreatic $\beta$ cells (Rajan et al., 2015). Three hours after injection, rats were transcardially perfused with 4\% paraformaldehyde in PBS followed by cryoprotection in $20 \%$ sucrose. This time point was selected based on previous research showing that the anorectic effects of central Ex- 4 do not develop until $3 \mathrm{~h}$ postadministration (Hayes et al., 2011; Kanoski et al., 2011, 2012). Brains were sectioned on a cryostat in the coronal plane at $30 \mu \mathrm{m}$. Hindbrain sections were collected at the level of the area postrema (from bregma, AP - 13.6 to $-14.2 \mathrm{~mm}$ ). Briefly, sections were blocked in $0.1 \mathrm{M}$ PBS containing $5 \%$ normal donkey serum and $0.2 \%$ Triton- $\mathrm{X}$ at room temperature. Sections were incubated in primary antibodies overnight, and then, following a PBS rinse, they were incubated in secondary antibodies for $2 \mathrm{~h}$. The primary antibodies used were rabbit anti-NeuN (1:1000; ab177487, Abcam) and goat anti-GFAP (1:1000; ab53554, Abcam). Secondary antibodies (Jackson ImmunoResearch) were donkey anti-goat Alexa Fluor 594 (1:500) and donkey anti-rabbit 7-amino-4-methylcoumarin-3acetic acid (AMCA; 1:200; see Figs. 2, 4; Movie 1) or donkey anti-rabbit Alexa Fluor 647 (1:500; see Fig. 3; Movie 2). Sections were visualized with a Leica SP5 X confocal microscope using the $20 \times$ and $63 \times$ oilimmersion objectives and the 405,488 , and 594 laser lines. Image $z$-stacks with the $63 \times$ oil-immersion were collected with a step size of $1 \mu \mathrm{m}$, while $2-3 \times$ optical zoom $z$-stack images using the same objective were collected with a step size of $0.5 \mu \mathrm{m}$. All images were collected sequentially to avoid contamination of signals from other fluorophores. Threedimensional rotational animations were rendered from the collected 


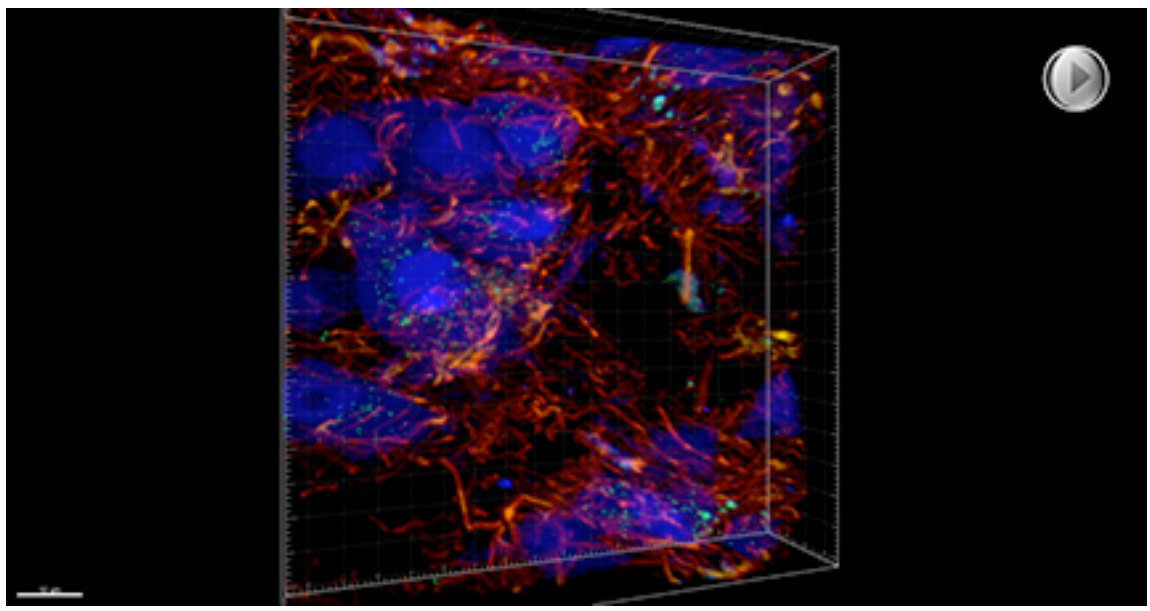

Movie 1. Representative three-dimensional rotational video of fluoro-Ex-4 colocalization in NTS astrocytes and neurons following systemic administration of fluoro-Ex-4. Rats $(n=2)$ were injected with fluoro-Ex-4 peripherally (10 $\mu \mathrm{g} / \mathrm{kg}$, i.p.) and killed $3 \mathrm{~h}$ later to label GLP-1R-expressing cells in the NTS. This video is taken from a $z$-stack ( $0.5 \mu \mathrm{m}$ step size) collected from the mNTS at the level of the area postrema with the $63 \times$ oil-immersion objective and a $2-3 \times$ optical zoom.

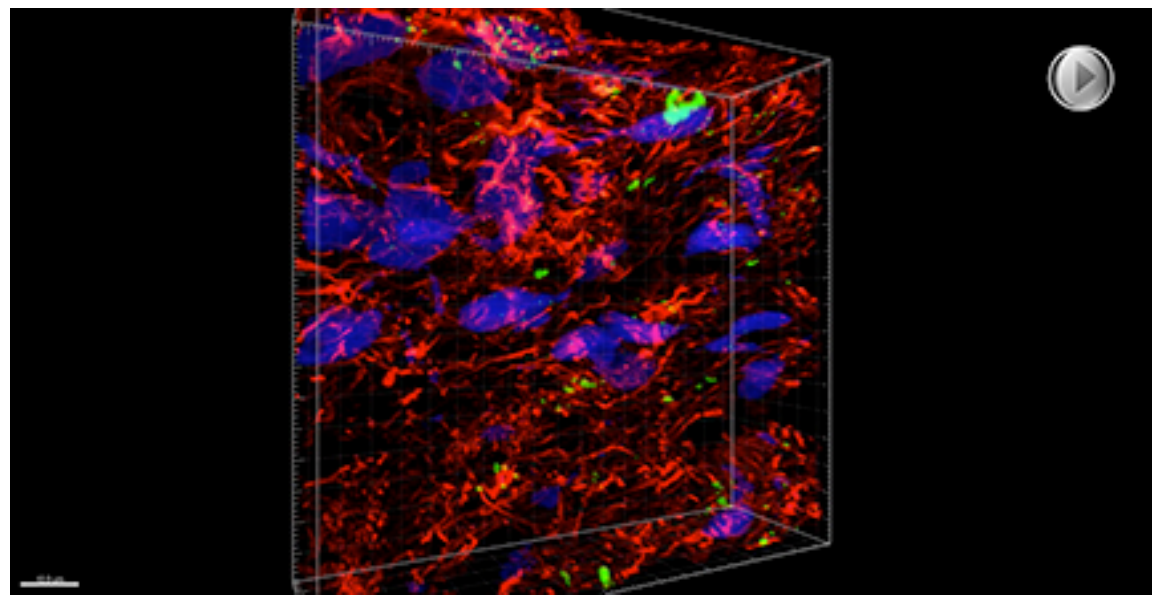

Movie 2. Internalization of systemically injected fluoro-Ex-4 in NTS cells is blocked by hindbrain pretreatment with a GLP-1R antagonist. Rats $(n=4)$ received a fourth cerebroventricle injection of Ex-9 (100 $\mu \mathrm{g}$ ) followed $20 \mathrm{~min}$ later by injection of fluoro-Ex-4 (10 $\mu \mathrm{g} / \mathrm{kg}$, i.p.). Three hours later, rats were killed to visualize GLP-1R-expressing NTS cells. This three-dimensional rotational video is taken from a z-stack ( 0.5 $\mu \mathrm{m}$ step size) from the mNTS at the level of the area postrema with the $63 \times$ oil-immersion objective and $2-3 \times$ optical zoom; a single image from this $z$-stack is shown in Figure $3 B$.

$z$-stack images using Imaris 8.1.2 (Bitplane). To generate these animations, a Gaussian blur was first applied to the green channel (fluoro-Ex-4) to smooth the background using default settings (filter size, $0.174 \mu \mathrm{m}$ ). For the blue channel $(\mathrm{NeuN})$, a median filter $(3 \times 3 \times 1$ pixels $)$ was applied. Finally, the thresholds and gamma settings were adjusted [green: thresholds, 4-40; gamma, 2.5; blue: thresholds, 2-90; gamma, 3; red (GFAP): thresholds, 2-200; gamma, 1.2].

To evaluate whether the uptake of fluoro-Ex-4 into cells is mediated by GLP-1R, separate rats were given a fourth cerebroventricle pretreatment with either the competitive GLP-1R antagonist exendin-(9-39) (Ex-9; $100 \mu \mathrm{g}$; American Peptide) or vehicle [2 $\mu$ l of artificial CSF (aCSF; Harvard Apparatus)] 20 min before intraperitoneal injection of fluoro-Ex-4 $(10 \mu \mathrm{g} / \mathrm{ml} / \mathrm{kg}$ ). Rats were transcardially perfused $3 \mathrm{~h}$ later (4\% paraformaldehyde in PBS followed by cryoprotection in $20 \%$ sucrose), and brains were immunohistochemically processed for NeuN, GFAP, and the fluorescently tagged Ex-4, as described above. Three-dimensional rotational animations were generated for Ex-9-treated sections, as described above. To evaluate colocalization of fluoro-Ex-4 in neurons and astro- cytes from animals in each treatment group, $z$-stacks were obtained from $63 \times$ with a $2-3 \times$ optical zoom (vehicle, $5 z$-stacks from three animals; Ex-9, $10 z$-stacks from three animals), and colocalization analysis was performed in Imaris (version 7.6.5). The Gaussian filter was applied to the green (fluoro-Ex-4) channel using default settings $(0.175 \mu \mathrm{m})$, the median filter was applied to the red (GFAP) and blue $($ NeuN) channels $(3 \times 3 \times 1$ pixels $)$, and an additional Gaussian filter was applied to the blue $(\mathrm{NeuN})$ channel $(0.175 \mu \mathrm{m})$. The Imaris Colocalization module was then run using manual threshold settings (green, 4; red, 5; blue, 2) to generate a colocalization channel and statistics were exported. For each treatment (vehicle or Ex-9), separate Pearson's correlation coefficients (PCCs) were generated for colocalization of green and red (fluoro-Ex-4 in astrocytes) and green and blue (fluoro-Ex-4 in neurons).

Triple labeling of GLP-1/GFAP/synaptophysin. Rats were perfused transcardially with ice-cooled $0.9 \%$ saline, followed by $4 \%$ paraformaldehyde in $0.1 \mathrm{~m}$ borate buffer at $\mathrm{pH} 9.5$. The brains were removed and immersed in fresh fixative containing $12 \%$ sucrose for $20-24 \mathrm{~h}$ at $4^{\circ} \mathrm{C}$. The brains were then blocked transversely at the level of the caudal midbrain, and each block was flash frozen in dry icecooled hexane before being sectioned frozen on a sliding microtome (transverse plane, 30 $\mu \mathrm{m}$ thickness, 5 series). Hindbrain sections were collected at the level of the area postrema (from bregma, AP -13.6 to $-14.2 \mathrm{~mm}$ ). Sections were stored in antifreeze solution at $-20^{\circ} \mathrm{C}$ until further processing.

For simultaneous immunohistochemical detection of GLP-1, GFAP, and synaptophysin, all washes and incubations were completed at room temperature, unless otherwise noted. All primary and secondary antibodies were diluted in a solution of potassium PBS (KPBS) containing 2\% donkey serum and $0.02 \%$ sodium azide. Three primary antibodies (rabbit antiGLP-1, goat anti-GFAP, and mouse antisynaptophysin) were used for this study. For each primary antibody used, a standard control was performed in which the primary antibody was omitted from the protocol (to control for a nonspecific signal resulting from subsequent antibody and signal detection reagents).

Tissue was washed with $0.02 \mathrm{M}$ KPBS to remove antifreeze, and then sections were permeabilized with $0.3 \%$ Triton X-100 in KPBS for 30 min. After KPBS washes, the tissue went through a blocking step of $30 \mathrm{~min}$ in $2 \%$ normal donkey serum at room temperature. Tissue was incubated overnight $(\sim 18 \mathrm{~h})$ at $2^{\circ} \mathrm{C}$ in rabbit anti-GLP-1 antibody $(1: 5000 ; \mathrm{T}-4363$, Peninsula Laboratories). After KPBS washes, tissue was incubated for 48 h with goat anti-GFAP (1:500; ab53554, Abcam) and mouse antisynaptophysin (1:1000; 61012, PROGEN Biotechnik). Next, sections were washed and then incubated overnight at $2^{\circ} \mathrm{C}$ in donkey anti-rabbit secondary-Cy3 conjugate (1:500; Jackson ImmunoResearch), donkey anti-goat secondary-AMCA conjugate (1:500; Jackson ImmunoResearch), and donkey anti-mouse secondary-AF488 conjugate (1:500; Jackson ImmunoResearch). Sections were mounted onto glass slides and coverslipped using 50\% glycerol in KPBS mountant. Photomicrographs were acquired as optical slices using a Zeiss LSM 700 UGRB confocal system controlled by Zeiss Zen software. 
Live cell calcium imaging

To prepare brainstem sections for live cell calcium imaging experiments, the dyes Calcium Green-1 AM (CG; Life Technologies) and sulforhodamine 101 (SR101; Invitrogen) were injected into the NTS of rats $(n=6)$, as previously described (Hermann et al., 2009; Vance et al., 2015). CAG is a calcium reporter dye that labels both neurons and astrocytes, while SR101 labels only astrocytes (McDougal et al., 2011), allowing us to discriminate between astrocytes and neurons in our imaging recordings. Cellular uptake of these dyes occurred within 30-45 min. The anesthetized rats were decapitated, and the brainstem was quickly harvested. Prelabeled brainstem was cut into coronal sections $(300 \mu \mathrm{m})$ on a vibrating microtome (VT1200, Leica) and submerged in a cold $\left(4^{\circ} \mathrm{C}\right)$ carbogenated $(95 \%$ $\mathrm{O}_{2} / 5 \% \mathrm{CO}_{2}$ ) cutting solution (for detailed descriptions, see Vance et al., 2015).

Live cell calcium imaging of prelabeled astrocytes and neurons was performed as previously described (Hermann et al., 2009; Vance et al., 2015). Hindbrain slices were placed in and acclimated to the recording chamber of a Nikon F1 fixed stage upright microscope with constant exposure to Krebs' recording solution. Each slice was exposed to only one of two experimental designs. In one experiment, the slice was exposed to $100 \mathrm{~nm} \mathrm{Ex}-4$ in the perfusion media for $80 \mathrm{~s}$, and responses were monitored for a minimum of $3 \mathrm{~min}$. In the other experiment, the slice was pretreated with the competitive GLP-1R antagonist Ex-9 (200 nм; Schepp et al., 1994) for $5 \mathrm{~min}$; then exposed to Ex-4 for $80 \mathrm{~s}$ and monitored for at least $3 \mathrm{~min}$. For both designs, slices were then washed out with normal Krebs' solution for $10 \mathrm{~min}$ and next were stimulated by exposure to Krebs' recording solution containing $100 \mu \mathrm{M}$ ATP and 500 $\mu \mathrm{M}$ L-glutamate for $80 \mathrm{~s}$. This ATP/glutamate challenge was used as a control to confirm that the neurons and astrocytes were viable and capable of producing calcium signals in response to experimental agonists. Only those cells (astrocytes and neurons) that responded to the ATP/ glutamate challenge were included in the response analysis. Our previous studies (Vance et al., 2015) have shown that response magnitudes of neurons or astrocytes to ATP/glutamate do not decline even after multiple exposures.

A Prairie Technologies (Bruker Corporation) line-scanning laser confocal head equipped with a Photometrics CoolSNAP HQ camera performed time-lapse laser confocal calcium imaging. Nikon Elements AR software was used to analyze the confocal live cell fluorescent signals in the astrocytes and neurons as previously described (Hermann et al., 2009; Vance et al., 2015). Individual astrocytes and neurons were designated as regions of interest (ROIs), and their fluorescence signal over time was captured. Background fluorescence was subtracted from the fluorescence signal. The relative changes in cytoplasmic calcium in the cells were expressed as changes in fluorescence $[(\Delta F / F) \%]$, where $F$ is the intensity of the baseline fluorescence signal before stimulation, and $\Delta F$ is the difference between the peak fluorescence intensity and the baseline signal. A minimum 5\% change in fluorescence per cell was required to be included in analysis (McDougal et al., 2011).

\section{Intracellular cAMP signaling response of immortalized medullary} rat astrocytes

Immortalized rat type- 1 astrocyte DI-TNC1 cells (ATCC) were maintained at $37^{\circ} \mathrm{C}$ in $5 \% \mathrm{CO}_{2}$ and were cultured in $1 \times$ DMEM with 4.5 $\mathrm{mg} / \mathrm{ml}$ glucose (Invitrogen), 10\% (v/v) fetal bovine serum (Thermo Fisher Scientific), and $2 \%$ penicillin $(10,000 \mathrm{IU} / \mathrm{ml})$-streptomycin $(10,000 \mu \mathrm{g} / \mathrm{ml})$ solution (Mediatech). Separate plates of DI-TNC1 cells were treated with one of the following three GLP-1R agonists: GLP-1 (American Peptide); Ex-4 (American Peptide); or liraglutide (Bachem). Three hour serum-starved DI-TNC1 astrocytes, cultured in a 96-well culture plate $(6 \times 104$ cells/well $)$, were treated with three doses of each b

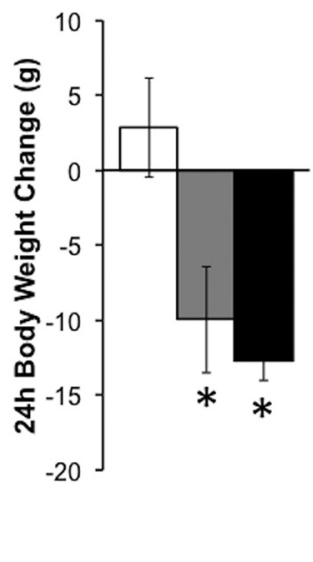

Time (h)

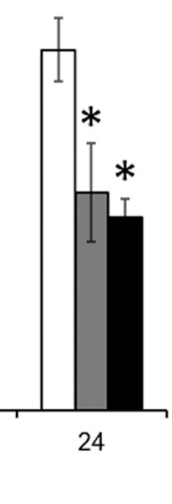
Figure 1. Hindbrain administration of fluorescently labeled Ex-4 produces energy balance effects comparable to those of
unlabeled Ex-4. $\boldsymbol{a}, \boldsymbol{b}$, Fourth cerebroventricle administration of Ex-4 $(0.3 \mu \mathrm{g})$ reduces chow intake $(\boldsymbol{a})$ and body weight gain $(\boldsymbol{b})$ in rats $(n=4)$; an equal dose of fluoro-Ex-4 given at the fourth cerebroventricle causes similar suppression of feeding and body weight gain. The key for $\boldsymbol{a}$ applies to both $\boldsymbol{a}$ and $\boldsymbol{b} .{ }^{*} p<0.05$ compared with vehicle. Data are shown as the mean \pm SEM.

agonist $(0.1,0.5$, or $1.0 \mathrm{nmol}$; three plates per agonist/dose combination) for $15 \mathrm{~min}$. cAMP levels were calculated using a standard curve of femtomoles of cAMP $/ 10^{4}$ DI-TNC1 cells. The same vehicle treatment $(n=9$ plates) was used for comparison with each GLP-1R agonist.

\section{Feeding behavior}

Comparison of fourth cerebroventricle Ex-4 versus fluorophore-labeled Ex-4. Approximately $15 \mathrm{~min}$ before dark cycle onset, ad libitum-fed rats $(n=4)$ received an injection of Ex-4 $(0.3 \mu$ g, i.c.v. $)$, fluorophore-labeled Ex-4 (0.3 $\mu$ g, i.c.v.), or vehicle (aCSF; $1 \mu$ l, i.c.v.). Doses of Ex-4 were chosen based on the literature (Hayes et al., 2011), and each rat received all treatments in a counterbalanced within-subjects design. At dark onset, rats were presented with preweighed chow, and intakes were recorded to the nearest $0.1 \mathrm{~g}$ at $1,3,6$, and $24 \mathrm{~h}$ post-food presentation. Body weights were recorded at 0 and $24 \mathrm{~h}$ after injection. Injections were separated by a minimum of $72 \mathrm{~h}$.

mNTS inhibition of astrocyte activity. Approximately $30 \mathrm{~min}$ before dark cycle onset, ad libitum-fed rats $(n=5)$ received a unilateral intramNTS pretreatment of vehicle $(100 \mathrm{nl}$ of $0.1 \mathrm{M}$ PBS $)$ or the astrocyte Krebs cycle inhibitor fluorocitrate (413 ng; DL-fluorocitric acid barium salt, Sigma-Aldrich) followed by a second unilateral mNTS injection of aCSF $(100 \mathrm{nl})$ or Ex-4 $(0.05 \mu \mathrm{g})$ in a within-subject counterbalanced design. At dark onset, rats were presented with preweighed chow, and intakes were recorded to the nearest $0.1 \mathrm{~g}$ at $1,3,6$, and $24 \mathrm{~h}$ post-food presentation. Body weights were recorded at 0 and $24 \mathrm{~h}$ after injection, and injections were separated by a minimum of $72 \mathrm{~h}$.

\section{Statistical analyses}

Data for all experiments are expressed as the mean \pm SEM, with significance set at $p<0.05$. To assess colocalization of fluoro-Ex-4 in NTS cells, PCCs for the different fourth cerebroventricle drug conditions (vehicle or Ex-9) were compared by separate two-tailed $t$ tests for each cell type (neurons or astrocytes). The PCC for astrocyte colocalization in one $z$-stack from an Ex-9-treated animal was a statistical outlier ( $>2$ SDs from the mean) and that $z$-stack was eliminated from all statistical analyses. In vitro cAMP data were analyzed by separate one-way ANOVAs, followed by Dunnett's post hoc analysis when the overall ANOVA was significant. For calcium imaging studies, data were evaluated using the Mann-Whitney $U$ test. Results of the feeding studies were analyzed by one-way or two-way mixed-design ANOVA, with drug condition as a within-subjects factor, and comparisons between treatment groups were made by Dunnett's (fourth cerebroventricle) or Student-NewmanKeuls (mNTS) post hoc tests. Analyses were performed using Statistica 12.0 or 13.0 (StatSoft). 

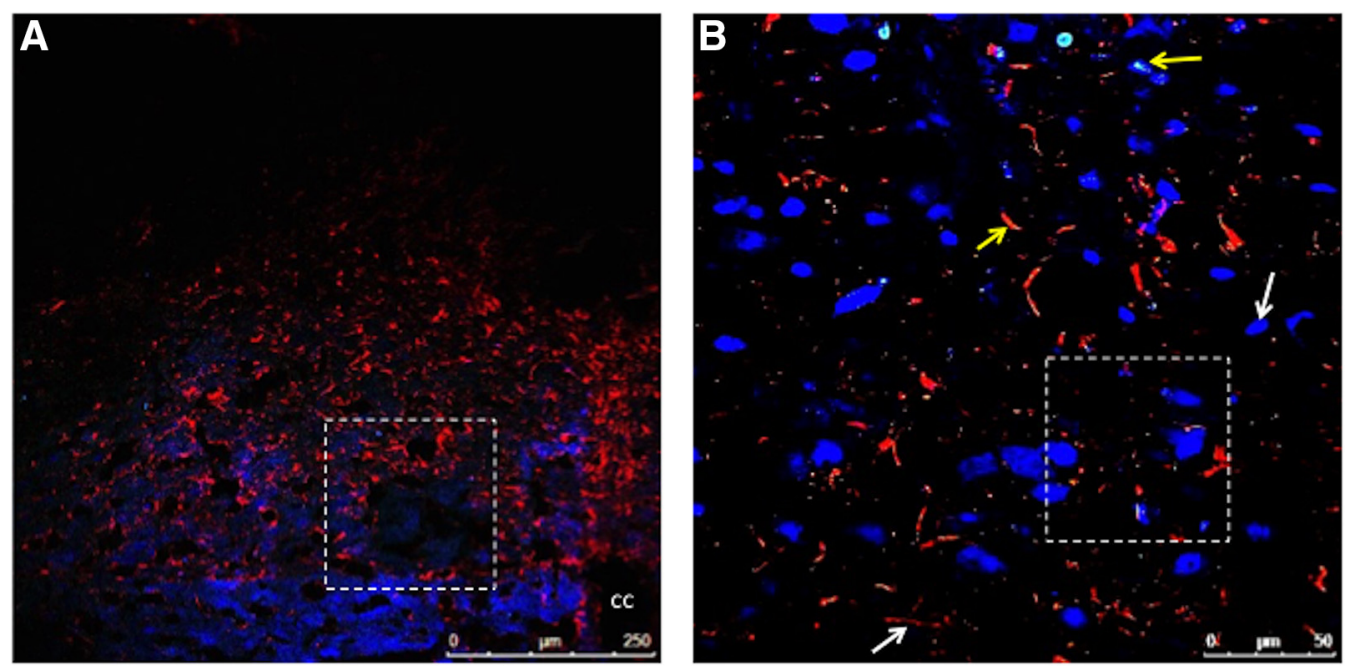

Figure 2. Fluorescently labeled Ex-4 is taken up by neurons and astrocytes within the NTS following systemic administration. Rats $(n=2)$ were injected with fluoro-Ex-4 peripherally $(10 \mu \mathrm{g} / \mathrm{kg}$, i.p.) and transcardially perfused $3 \mathrm{~h}$ later. A representative NTS-containing section is shown at $20 \times$ magnification in $A$, with GFAP-positive cells shown in red and NeuN-positive cells in blue. The dotted box outlined in $\boldsymbol{A}$ is magnified in $\boldsymbol{B}$. This higher-magnification image in $\boldsymbol{B}$ depicts a single image within a $z$-stack $(0.5 \mu \mathrm{m}$ step size) taken with the $63 \times$ oil-immersion objective shows fluoro-Ex-4 labeling in GFAP-positive cells (red) and NeuN-positive cells (blue). White arrows indicate cells lacking colocalization with fluoro-Ex-4, while yellow arrows indicate cells that take up fluoro-Ex-4. The dotted box in $\boldsymbol{B}$ indicates the field of view in Movie 1. cc, Central canal.
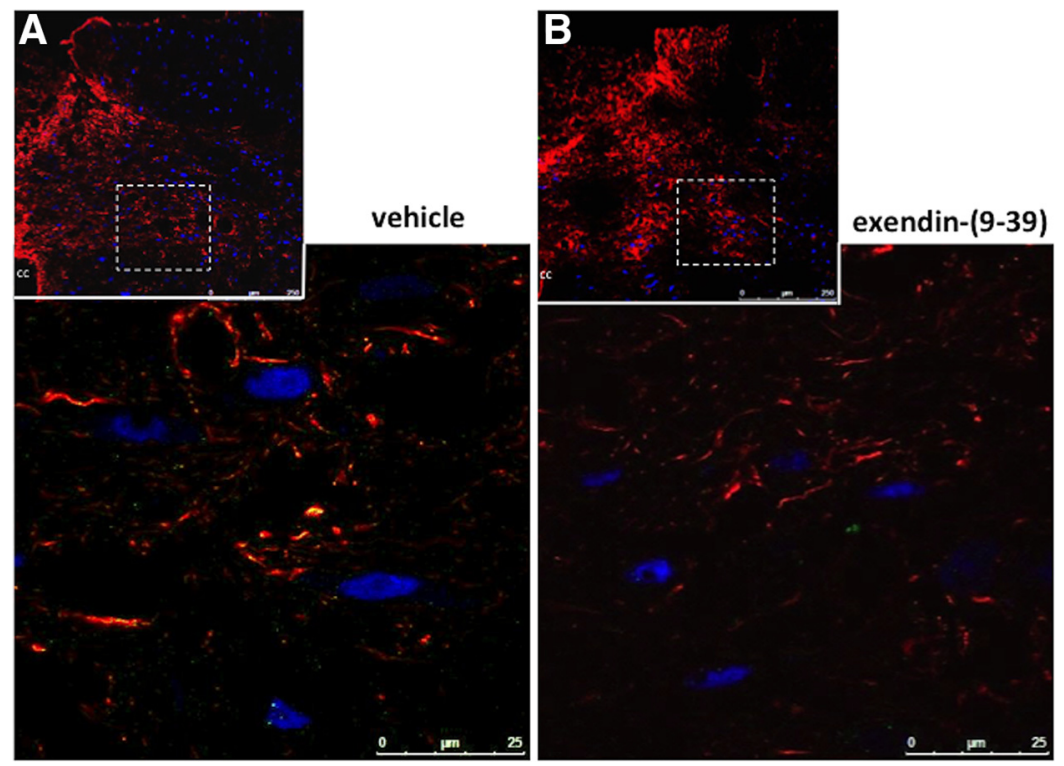

Figure 3. The internalization of peripherally administered fluoro-Ex-4 in NTS cells is blocked by fourth cerebroventricle pretreatment with a GLP-1Rantagonist. $A, B$, While uptake of fluoro-Ex-4 (10 $\mu \mathrm{g} / \mathrm{kg}$, i.p.) was observed in NTS astrocytes and neurons of rats given a fourth cerebroventricle pretreatment with vehicle $(\boldsymbol{A} ; n=3)$, central pretreatment with $\mathrm{Ex}-9$ (100 $\mu \mathrm{g})$ blocked this effect ( $\boldsymbol{B} ; n=4$; see also Movie 2). Fluoro-Ex-4 is shown in green, GFAP-positive cells are shown in red, and NeuN-positive neurons are shown in blue. The smaller insets at the top of each panel depict representative NTS-containing coronal sections at 20X magnification. The boxed area of each inset was magnified to $63 \times$ and a further $2-3 \times$ optical zoom was applied to generate the large images. cc, Central canal.

\section{Results}

Astrocytes and neurons in the NTS express GLP-1 receptors and internalize GLP-1R ligands

To provide anatomical evidence that GLP-1Rs are expressed on astrocytes in the NTS, we tested the uptake of a fluorophorelabeled version of the GLP-1R agonist exendin-4 (fluoro-Ex-4) by neurons and astrocytes in the NTS, given the lack of a validated commercially available GLP-1R-selective antibody. First, we verified that fluoro-Ex-4 has a comparable pharmacokinetic profile of effect on food intake and body weight as an equal dose of unlabeled Ex-4 when administered at the fourth cerebroventricle in rats (Fig. 1; feeding, $F_{(2,6)}=6.92, p=0.03$; body weight gain, $F_{(2,6)}=6.36, p=0.03$; for both feeding and body weight gain; vehicle vs Ex-4 or fluoro-Ex-4, $p<0.05$; Ex-4 vs fluoro-Ex-4, $p>0.05$ ). Fluoro-Ex-4 was then injected at the fourth cerebroventricle $(0.3 \mu \mathrm{g})$ or systemically (10 $\mu \mathrm{g} / \mathrm{kg}$, i.p.), and the animals were transcardially perfused $3 \mathrm{~h}$ later. The brains were immunohistochemically processed to label astrocytes and neurons, in conjunction with visualization of fluoroEx-4. Confocal microscopy revealed colocalization of fluoro-Ex-4 in both GFAP-positive astrocytes and NeuNpositive neurons in the NTS following either systemic or fourth cerebroventricle delivery (Figs. 2, 4). Further, a threedimensional rotation video of $63 \times$ $z$-stack overlays within the NTS revealed that systemically delivered fluoro-Ex-4 was internalized by both NTS astrocytes and neurons (Movie 1). This movie avoids the possibility of false overlaps that may exist in the two-dimensional image (e.g., fluoro-Ex-4 directly in front of or behind the cell may appear to be colocalized in a two-dimensional image, but not in a three-dimensional rotation).

To confirm that the binding and uptake of fluoro-Ex-4 in NTS cells is mediated by GLP-1R, we tested whether internalization of peripherally administered fluoro-Ex-4 would be attenuated by pharmacological blockade of hindbrain GLP-1Rs. As shown in Figure $3 A$, similar to our first study, fluoro-Ex-4 was colocalized in both astrocytes and neurons in the NTS after fourth cerebroventricle pretreatment with vehicle $(2 \mu \mathrm{l})$. However, hindbrain injection of the competitive GLP-1R antagonist Ex-9 (100 

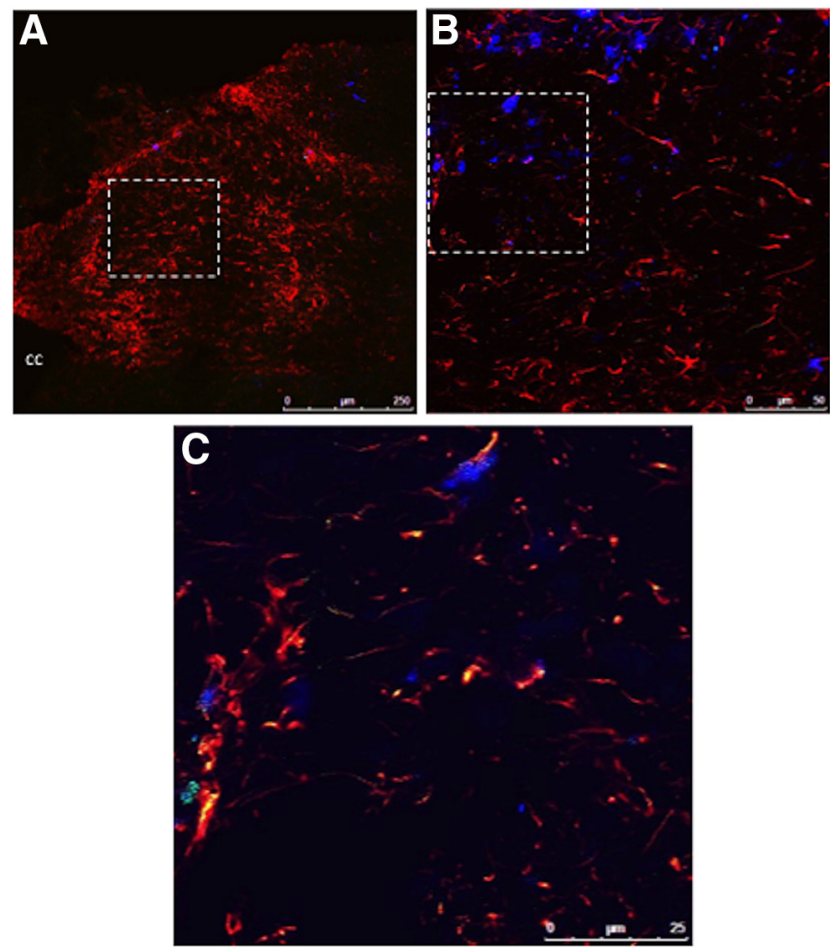

Figure 4. Fluorescently labeled $\mathrm{Ex}-4$ is taken up by neurons and astrocytes within the NTS following fourth cerebroventricle administration. Rats $(n=3)$ were injected with fluoro-Ex-4 $(0.3 \mu$ g, i.c.v.) and killed $3 \mathrm{~h}$ later. $A, B, A$ representative NTS-containing brain section is shown at 20× magnification in $A$, with GFAP-positive cells shown in red and NeuN-positive cells in blue. The dotted box outlined in $\boldsymbol{A}$ is magnified in $\boldsymbol{B}$. This higher-magnification image in $\boldsymbol{B}$ shows a single image within a $z$-stack ( $1 \mu \mathrm{m}$ step size) taken with the $63 \times$ oil-immersion objective and depicts fluoro-Ex-4 labeling in GFAP-positive cells (red) and NeuN-positive cells (blue). The dotted rectangle indicates the location of an additional 2-3× optical zoom represented in $C$ within the same $z$-stack ( $0.5 \mu \mathrm{m}$ step size). cc, Central canal.

$\mu \mathrm{g}$ ) blocked the uptake of fluoro-Ex-4 in NTS cells (Fig. 3B; Movie 2, three-dimensional rotational video). Quantitative analyses suggest that Ex-9 pretreatment blocks colocalization of fluoro-Ex-4 in both astrocytes (vehicle, $r=0.20 \pm 0.12$; Ex-9, $r=$ $-0.07 \pm 0.03 ; t_{(12)}=2.75, p=0.02$ ) and neurons (vehicle, $r=$ $0.23 \pm 0.10$; Ex-9, $\left.r=0.03 \pm 0.04 ; t_{(12)}=2.36, p=0.04\right)$. Although this analysis does not account for the location of the fluoro-Ex-4 (e.g., on the cell surface vs internalized), as Ex-9 is a competitive GLP-1R antagonist, it would likely block both receptor binding and internalization of the agonist. Collectively, these data provide further evidence that uptake of the fluorescently tagged Ex-4, like untagged Ex-4, is mediated by the GLP-1R. Again, the inclusion of Movie 2 avoids the potential for false overlaps in the two-dimensional image in Figure $3 B$.

These data provide novel anatomical evidence suggesting that astrocytes bind and take up GLP-1R ligands; these results also show that a peripherally injected GLP-1R agonist can penetrate the blood-brain barrier and gain access to the NTS. Furthermore, these data show that a portion of astrocytes and neurons do not take up the fluoro-Ex-4, suggesting that these cells do not express the GLP-1R, while other cells in adjacent proximity show clear uptake of the fluoro-Ex-4 and putatively express GLP-1Rs (shown explicitly in Fig. 2).

NTS astrocytes and neurons show increased live cell calcium signaling following Ex-4-induced GLP-1R activation To test the ability of astrocytes in the NTS to respond to GLP-1R activation, ex vivo live cell calcium signaling in NTS-containing rat

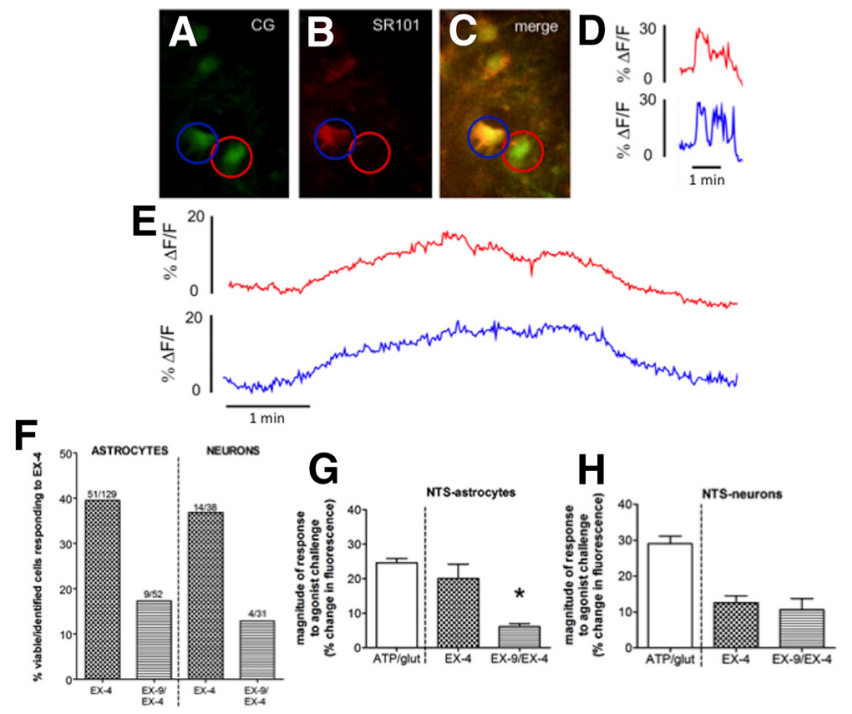

Figure 5. GLP-1R activation increases calcium signaling in subsets of both NTS astrocytes and neurons. $A-C$, NTS cells ( $n=6$ rats) were preloaded with Calcium Green-1 AM (calcium-sensitive dye; labels astrocytes and neurons) and SR101 (astrocyte-specific red dye); yellow colocalization confirms that the calcium-sensitive dye is localized in astrocytes. Astrocytes and neurons are designated as a ROl; red, neuron; blue, astrocyte. Calcium-induced changes in fluorescence in response to perfusion parameters are quantitated over time. The percentage change in fluorescence for each ROl over time is shown in corresponding line colors (neuron in red, astrocyte in blue). Control (viability) experiments were performed (representative traces in D) in which a cocktail of ATP/glutamate was applied for 80 s to identify viable, responsive astrocytes and neurons (i.e., increased intracellular calcium as demonstrated by increased fluorescence). The increase in intracellular calcium is immediate due to the combined opening of ligand-gated cation channels and the intracellular release of stored calcium. $\boldsymbol{E}, \boldsymbol{F}$, Approximately $40 \%$ of NTS astrocytes and neurons was also activated by GLP-1R agonist Ex-4 (representative traces in $\boldsymbol{E}$, quantification of cells in $\boldsymbol{F}$ ). Pre-exposure of the slice to the competitive GLP-1R antagonist Ex-9 reduces the number of Ex-4-responsive cells to $\sim 20 \%(\boldsymbol{F})$. $\boldsymbol{G}$, The subpopulation of NTS astrocytes activated by Ex-4 exhibits a similar magnitude of calcium response as that elicited by the ATP/glutamate cocktail, but pre-exposure to Ex-9 reduces the magnitude of this response. $\boldsymbol{H}, \mathrm{In}$ contrast, the magnitude of the calcium response in neurons to $\mathrm{Ex}-4$ was not further inhibited by $\mathrm{Ex}-9$. For $\boldsymbol{G}$ and $\boldsymbol{H}$, data are shown as the mean $\pm \operatorname{SEM}^{*} p<0.05$.

brainstem slices was evaluated following bath application of Ex-4 $(100 \mathrm{nM})$. Astrocytes were prelabeled with the astrocyte-specific dye SR101, and both astrocytes and neurons were prelabeled with the calcium-sensitive dye CG (Fig. 5A-C). An increase in intracellular calcium corresponded to an increase in fluorescence and is indicative of cellular activation (Rogers et al., 2006). In viability experiments, ATP/glutamate stimulation activated 129 NTS astrocytes with a mean magnitude of increased fluorescence of $24.6 \pm 1.2 \%$ (Fig. $5 D, F, G$ ). Of the 129 NTS astrocytes responsive to the ATP/ glutamate challenge, $40 \%$ were also directly responsive to Ex-4 stimulation (Fig. $5 E, F$ ) with a $20.1 \pm 4.2 \%$ mean magnitude of response (Fig. $5 G$ ), which is similar in magnitude to the response to ATP/ glutamate. A similar proportion of NTS neurons was responsive to Ex-4 stimulation (14 of 38 ATP/glutamate-responsive neurons; Fig. $5 E, F)$. Those neurons that were responsive to both stimuli averaged lower magnitudes in their response to Ex-4 relative to their evoked response to ATP/glutamate (Fig. $5 H$ ).

In separate hindbrain slices, pre-exposure to the competitive GLP-1R antagonist Ex-9 reduced the overall number of Ex-4responsive astrocytes from $40 \%$ to $\sim 20 \%$ (Fig. $5 F$ ). NTS astrocytes that were still activated by Ex- 4 following Ex-9 pre-exposure had a significantly diminished response to Ex-4 (Fig. 5G; $U=37$, $p=0.0002$ ). In contrast, while Ex-9 suppressed the number of NTS neurons responsive to Ex -4 from $\sim 37 \%$ to $13 \%$ (Fig. $5 F$ ), the magnitude of their response to Ex-4 was not further inhibited by Ex-9 (Fig. $5 H ; U=20, p=0.53$ ). 

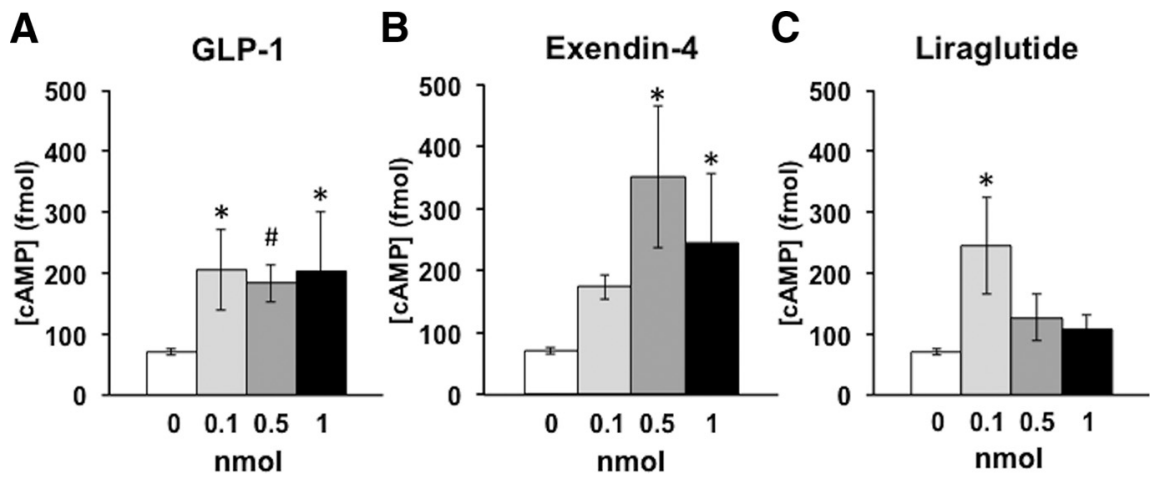

Figure 6. GLP-1R activation increases CAMP concentration in astrocytes in vitro. $\boldsymbol{A}-\boldsymbol{C}$, Bath application of the GLP-1R agonists GLP-1 $(\boldsymbol{A})$, Ex-4 (B) , or liraglutide ( $\boldsymbol{C}$ ) elevated cAMP levels in immortalized rat type-1 astrocytes (DI-TNC1). For each agonist/dose combination, $n=3$ plates of cells; for control, $n=9$ plates of cells. Data shown as the mean \pm SEM. ${ }^{*} p<0.05 ; \# p<0.08$ compared with control (dose 0 ).

\section{GLP-1R activation increases cAMP in astrocytes in vitro}

Downstream intracellular signaling events of GLP-1R activation in neurons include elevated levels of cAMP and protein kinase A, which are required for the anorexigenic effects of GLP-1R activation (Hayes et al., 2011). However, it is unknown whether this signaling pathway is also recruited by astrocytic GLP-1R activation. To determine whether GLP-1R activation increases cAMP levels specifically in astrocytes, we measured cAMP concentration in an immortalized rat type-1 astrocyte cell line (DI-TNC1) after exposure to one of three GLP-1R agonists [GLP-1(7-36), exendin-4 (Ex-4), or liraglutide; $0.1,0.5,1.0 \mathrm{nmol}]$. These in vitro analyses demonstrated that each of the three GLP-1R ligands caused a significant dose-dependent increase in cAMP concentrations in astrocytes (Fig. 6; GLP-1: $F_{(3,14)}=3.74, p=0.04 ; \mathrm{Ex}-4: F_{(3,14)}=6.02$, $p=0.01$; liraglutide: $\left.F_{(3,14)}=6.12, p=0.01\right)$. These data suggest that, like the cAMP responses previously observed in neurons (Hayes et al., 2011), cAMP signaling is engaged downstream of GLP-1R activation in astrocytes.

\section{Endogenous GLP-1-immunopositive fibers form synaptic contact with NTS astrocytes}

To provide evidence of a potential endogenous source of GLP-1 to NTS astrocytes, immunohistochemical triple labeling was performed to identify GLP-1 axons, astrocytes (GFAP immunopositive), and presynaptic terminals (synaptophysin immunopositive) in the NTS of rats. As shown in Figure 7, GLP-1 and synaptophysin colocalized in NTS GFAP-positive astrocytes, indicating that GLP-1 axons terminate in close apposition (presumably synaptic contacts) to NTS GFAP-positive astrocytes. These anatomical data suggest that NTS PPG neurons are a putative endogenous source of GLP-1 to NTS astrocytes.

\section{Astrocytes mediate the food intake- and body weight- suppressive effects of GLP-1R activation in the NTS}

To test whether NTS astrocytes play a role in the energy balance effects of GLP-1R activation, food intake and body weight gain were measured in rats following NTS-targeted treatment with the astrocyte Krebs cycle inhibitor fluorocitrate (413 ng; Lian and Stringer, 2004; Hermann et al., 2014) and Ex-4 (0.05 $\mu \mathrm{g})$. As shown in Figure 8, NTS pretreatment with fluorocitrate attenuated both the hypophagia and body weight reduction produced by direct NTS administration of Ex-4 [ $24 \mathrm{~h}$ food intake: interaction between fluorocitrate and $\mathrm{Ex}-4, F_{(1,4)}=10.08, p=0.03$; body weight: $F_{(1,4)}=33.87, p=0.004$; for both $24 \mathrm{~h}$ food intake and body weight, vehicle/vehicle vs vehicle/Ex-4, $p<0.05$;
vehicle/Ex-4 vs fluorocitrate/Ex-4, $p<$ 0.05 ; no statistically significant interaction between fluorocitrate and Ex-4 at 1, 3 , or $6 \mathrm{~h}\left(\right.$ all $F_{(1,4)} \leq 1.04$, all $p \geq 0.37$; data not shown)]. These findings suggest that inhibiting astrocyte activity attenuates the ability of NTS GLP-1R activation to promote negative energy balance.

\section{Discussion}

Astrocytes play a critical role in regulating glutamatergic neurotransmission, yet are surprisingly understudied as potential mediators of energy balance-relevant signals. Given that the food intake- and body weight-suppressive effects of central GLP-1R signaling are mediated in part by presynaptic modulation of glutamate signaling (Hisadome et al., 2011; MietlickiBaase et al., 2013, 2014), it is intriguing to consider the idea that GLP-1Rs expressed on astrocytes may influence glutamate signaling to affect energy balance. We focused our attention on astrocytes in the NTS because of the critical role this nucleus serves in processing vagally mediated glutamatergic satiation signals (Grill and Hayes, 2012), as well as the endogenous relevance of NTS GLP-1R signaling for the control of feeding (Hayes et al., 2009). Novel data presented here show the following: (1) that astrocytes are activated by GLP-1 and GLP-1R agonists; (2) that the GLP-1R agonist Ex-4 is internalized by and produces robust calcium signaling in NTS neurons and astrocytes; (3) that endogenous central GLP-1 neurons form close synaptic appositions with NTS astrocytes; and (4) that NTS astrocyte activity is required for the hypophagia and reduction in body weight produced by NTS GLP-1R activation.

Unlike the short half-life of endogenous peripheral GLP-1, systemically administered GLP-1R agonists Ex-4 and liraglutide are resistant to degradation by dipeptidyl peptidase- 4 and thus remain in circulation for longer periods of time to impact energy balance (Kanoski et al., 2011; Secher et al., 2014; Sisley et al., 2014). These drugs are used clinically for the treatment of T2DM, and more recently, liraglutide also has been approved by the FDA for the treatment of obesity (Tella and Rendell, 2015), highlighting the importance of fully understanding the mechanisms by which these GLP-1R agonists exert their metabolic effects. To address the ability of GLP-1R agonists to activate NTS astrocytes, an important first step was to confirm GLP-1R expression on astrocytes. Given the lack of a validated commercially available GLP-1R-selective antibody, we instead availed ourselves of a novel use of fluorophore-tagged Ex-4 and tested its ability to label GLP-1R-expressing cells in the NTS. Injection of fluoro-Ex-4 either centrally or peripherally revealed that some, but not all, NTS astrocytes and neurons were labeled with the fluorescent tag, indicating binding of the ligand and thus probable GLP-1R expression. The finding that uptake of peripherally administered fluoro-Ex-4 was blocked by hindbrain pretreatment with Ex-9 further supports GLP-1R mediation of these effects. These results also provide visual evidence that this long-lasting GLP-1R agonist can cross the blood-brain barrier and bind to receptors within the CNS. Perhaps most intriguing is the discovery that fluoro-Ex-4 was internalized not only by neurons (Secher et al., 2014), but also by astrocytes. Unsurprisingly, there was more robust fluoro-Ex-4 labeling on NTS neurons and astrocytes when the drug was injected at the fourth cerebroventricle compared with peripheral injection. It is possible that this effect is due not just to the concentration of the localized injection, but may also be a secondary consequence of in- 

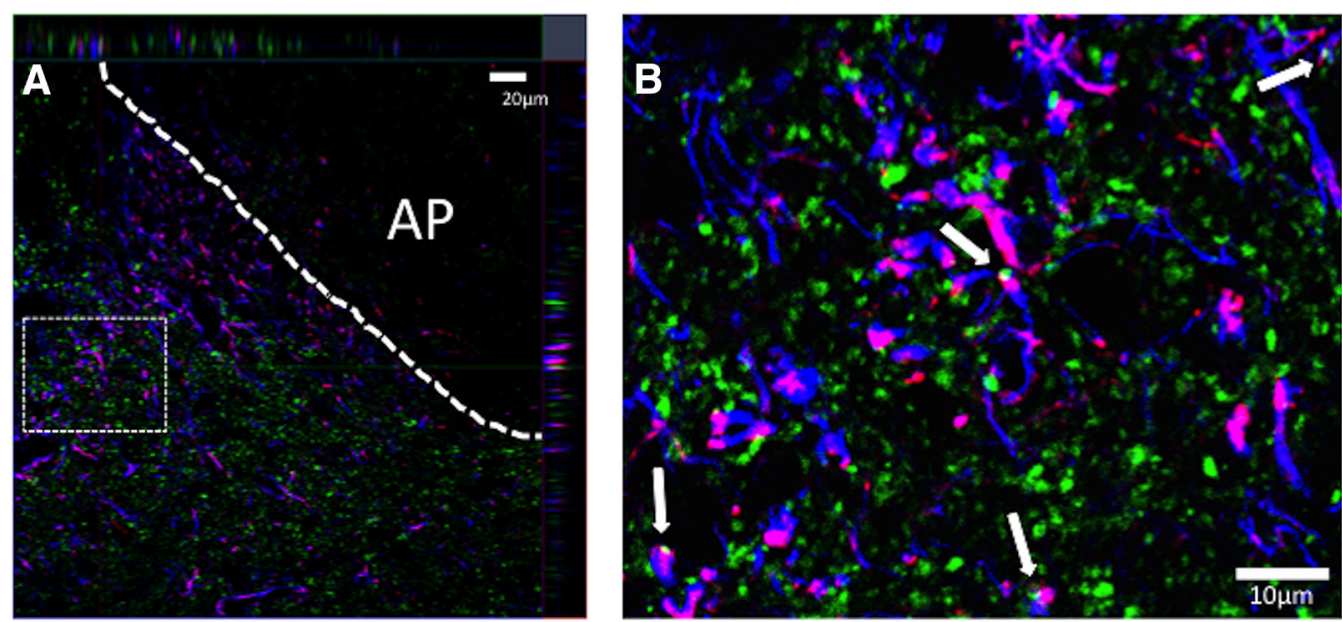

Figure 7. GLP-1-containing axons form close appositions with NTS astrocytes. Representative 1.5- $\mu \mathrm{m}$-thick images from NTS-containing transverse sections ( $n=3$ rats) show GLP-1 in red, GFAP (astrocyte marker) in blue, and synaptophysin in green. White arrows indicate triple labeling, providing evidence for synaptic-like contacts between GLP-1-containing cells and astrocytes in the NTS. The top orthogonal in $\boldsymbol{A}$ represents the $x-z$ plane for the $z$-stack, whereas the right orthogonal represents the $y-z$ plane for the $z$-stack. The cross hairs in this panel (red vertical line meets green horizontal line) highlight one of several examples of three-label evidence for appositions at this level of the NTS. The inset in $\boldsymbol{B}$ reveals this at higher resolution, with the three-label example at the cross hairs in $\boldsymbol{A}$ represented by the top arrow in $\boldsymbol{B}$. AP, Area postrema.

creased GLP-1R expression in glia following fourth cerebroventricle surgery (Chowen et al., 1999). Thus, there is a clear need for future dose-response and time-course experiments to fully evaluate the penetrance and uptake of fluoro-Ex-4 throughout the CNS following both systemic and central injections.

A combination of in vitro and ex vivo approaches was used to demonstrate that astrocytes not only internalize a GLP-1R agonist, but also are responsive to GLP-1R activation. Ex vivo live cell calcium imaging data indicated that subpopulations of astrocytes and neurons within the NTS are responsive to GLP-1R activation. Approximately $40 \%$ of all viable NTS astrocytes and neurons also responded to Ex-4. However, pre-exposure of the slice to Ex-9 reduced the numbers of NTS astrocytes and neurons responding to Ex-4. Furthermore, the magnitude of the NTS astrocyte response to Ex-4 was reduced by Ex-9; in contrast, Ex-9 pretreatment did not further blunt the magnitude of response to Ex-4 in neurons that remained responsive. This observation opens the possibility that NTS neuron responses to Ex-4 may be activated, at least in part, by an indirect gliotransmission-driven pathway following GLP-1R activation of astrocytes.

To directly examine whether GLP-1R-mediated calcium signaling engages cAMP as a second messenger in astrocytes, an immortalized rat type-1 astrocyte DI-TNC1 cell line was used. Similar to the response previously observed in neuronal cultures (Hayes et al., 2011), cAMP levels increased dose dependently in the astrocyte cell line following activation by any one of three GLP-1R agonists tested (GLP-1, Ex-4, or liraglutide). These data suggest that GLP-1R activation and recruitment of the appropriate intracellular signaling cascades occur not only in neurons but also in astrocytes.
B

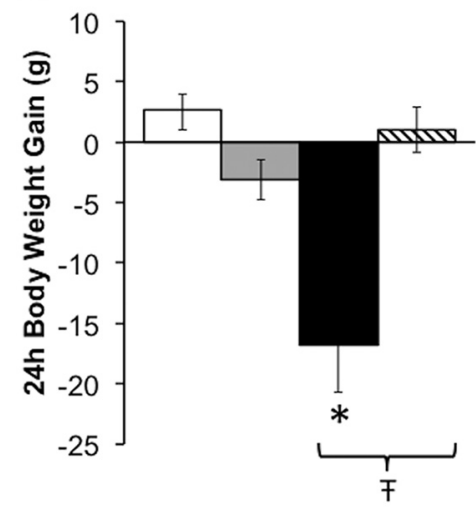

Vehicle / Exendin-4

Fluorocitrate / Exendin-4

Figure 8. Inhibition of mNTS astrocytes attenuates the food intake- and body weight-suppressive effects of mNTS GLP-1R activation. Rats $(n=5)$ were given an intra-mNTS pretreatment with the astrocyte Krebs cycle inhibitor fluorocitrate or its vehicle, weight gain $(\boldsymbol{B})$ over the $24 \mathrm{~h}$ postinjection. *Significantly different from vehicle/vehicle $(p<0.05) ; \mathrm{F} p<0.05$ vs vehicle/Ex-4. Key applies to both panels. Data are shown as the mean \pm SEM.

Previous research has shown that endogenous NTS GLP-1R signaling is physiologically relevant for food intake control, as blockade of endogenous NTS GLP-1R by hindbrain administration of Ex-9 leads to a significant increase in food intake (Hayes et al., 2009). However, it is unknown whether this effect is due to blockade of GLP-1R expressed on NTS neurons, astrocytes, and/or vagal afferent terminals. Given that NTS PPG neurons synthesize GLP-1, endogenous GLP-1 produced within the NTS could engage astrocytes for energy balance control. Indeed, the novel immunohistochemical analyses presented here provide anatomical evidence that endogenous GLP- 1 axons make close appositions with NTS astrocytes. This finding does not establish whether these points of contact are classic "synapses," and it remains unclear whether true synaptic communication occurs at these apposed membranes or whether the GLP-1 axons and NTS astrocytes interact in some other way. Nevertheless, 
these close appositions suggest an interaction between the GLP-1producing neurons and astrocytes, and future studies are warranted to examine the contribution of endogenous, astrocyte-specific GLP-1R signaling for energy balance control.

Behavioral food intake and body weight analyses demonstrated that inhibition of NTS astrocyte metabolic function with fluorocitrate attenuated the intake and body weight suppression produced by NTS GLP-1R activation. This finding supports the hypothesis that NTS astrocytes not only bind, internalize, and display appropriate signaling responses to GLP-1R agonists, but also that NTS astrocytes mediate the energy balance effects of GLP-1R signaling. Fluorocitrate inhibits glial cells by blocking aconitase activity, thereby disrupting the tricarboxylic acid cycle (Peters, 1957; Brand et al., 1973; Fonnum et al., 1997). Although multiple types of glia can be inhibited by fluorocitrate, it appears to have the most potent effects on astrocytes (Paulsen et al., 1987). Any potential influence of oligodendrocytes or microglia on the behavioral effects observed in this experiment would likely be minimal compared with astrocytic contributions, but this possibility cannot be ruled out. At very high doses, fluorocitrate can also disrupt neuronal activity (Koenig, 1969), but the dose used in our study (413 $\mathrm{ng}$ or $0.5 \mathrm{nmol}$ ) is far below subthreshold concentrations for neuronal effects (Paulsen et al., 1987; Hassel et al., 1992; Willoughby et al., 2003).

As fluorocitrate blocks all astrocyte activity, it is impossible to tease apart the exact role of astrocytes in mediating GLP-1R intake suppression by this pharmacological manipulation. For example, we cannot definitively exclude the possibility that astrocytes are indirectly involved with the behavioral effects of GLP-1R activation. That is, NTS fluorocitrate injection will nonselectively inhibit all NTS astrocytes, not only GLP-1R-expressing astrocytes, so one cannot rule out the alternative explanation that astrocytes are engaged along with or even downstream of neuronal GLP-1R activation, or that non-GLP-1R-expressing astrocytes may play some indirect role in these anorexic effects. However, the results of the calcium imaging studies argue against these possibilities. The near-simultaneous activation of NTS astrocytes and neurons by Ex-4 in that experiment supports the hypothesis that Ex-4 acts directly on at least a subset of NTS astrocytes. Even if GLP-1R activation in these astrocytes accompanies neuronal GLP-1R activation, our behavioral data suggest that astrocytes are required for the control of energy balance by NTS GLP-1R activation.

An important empirical question arising from these studies is the mechanism by which astrocytic GLP-1R activation might alter glutamatergic neurotransmission to affect energy balance. Increased cAMP levels have been linked to reduced expression of glutamate transporters (Lim et al., 2005). Our data demonstrating that astrocytic GLP-1R activation elevates cAMP hints at the intriguing possibility that astrocytic glutamate transporters (e.g., GLT-1, GLAST) may be downregulated as a result of GLP-1R activation, providing a potential mechanism by which GLP-1R signaling in astrocytes could increase glutamate levels in the NTS synapse and consequently reduce food intake (Ritter, 2004; Hisadome et al., 2011; MietlickiBaase et al., 2013, 2014). GLP-1R activation also increases interleukin signaling (Shirazi et al., 2013). As interleukins can block the ability of astrocytes to take up glutamate from the synapse (Takahashi et al., 2003), this offers an additional possible mechanism by which astrocytic GLP-1R activation may alter synaptic glutamatergic signaling. Interestingly, cytokines can also sensitize vagal afferent signaling (Hermann and Rogers, 2008). Thus, NTS GLP-1R activation, including activation of receptors on astrocytes, may directly inhibit glutamate reuptake and engage cytokine signaling to enhance synaptic glutamate levels, while simultaneously enhancing incoming vagal neurotransmission to affect subsequent feeding behavior.

Collectively, the current data show that NTS astrocytes are engaged by GLP-1R activation to control energy balance. Central activation of GLP-1R in a variety of nuclei has a broad range of behavioral and physiological effects. In addition to the NTS, several nuclei within the brain mediate the hypophagic effects of GLP-1 (Hayes et al., 2014). Additionally, CNS GLP-1R mediate diverse phenomena including glycemic control (Sandoval et al., 2008), motivated behavior (Harasta et al., 2015), and even presumably protection against neurodegeneration (Bao et al., 2015). The possibility that astrocytic GLP-1R activation contributes to these effects is just beginning to be considered. As FDA-approved drugs such as Ex-4 and liraglutide target the central GLP-1 system, the present findings may also be of clinical significance as the scientific community strives to comprehend more fully the mechanisms by which GLP-1R agonists exert their physiological and behavioral effects. In summary, the current findings not only demonstrate the importance of NTS astrocytic GLP-1R signaling for food intake control, but also represent the beginning of an enormous opportunity for deeper understanding of the mechanisms by which central GLP-1 signaling influences physiology and behavior.

\section{References}

Acuna-Goycolea C, van den Pol A (2004) Glucagon-like peptide 1 excites hypocretin/orexin neurons by direct and indirect mechanisms: implications for viscera-mediated arousal. J Neurosci 24:8141-8152. CrossRef Medline

Alhadeff AL, Rupprecht LE, Hayes MR (2012) GLP-1 neurons in the nucleus of the solitary tract project directly to the ventral tegmental area and nucleus accumbens to control for food intake. Endocrinology 153: 647-658. CrossRef Medline

Alhadeff AL, Baird JP, Swick JC, Hayes MR, Grill HJ (2014) Glucagon-like Peptide-1 receptor signaling in the lateral parabrachial nucleus contributes to the control of food intake and motivation to feed. Neuropsychopharmacology 39:2233-2243. CrossRef Medline

Amato A, Cinci L, Rotondo A, Serio R, Faussone-Pellegrini MS, Vannucchi MG, Mulè F (2010) Peripheral motor action of glucagon-like peptide-1 through enteric neuronal receptors. Neurogastroenterol Motil 22: 664-e203. CrossRef Medline

Bao Y, Jiang L, Chen H, Zou J, Liu Z, Shi Y (2015) The neuroprotective effect of liraglutide is mediated by glucagon-like peptide 1 receptor-mediated activation of cAMP/PKA/CREB pathway. Cell Physiol Biochem 36: 2366-2378. CrossRef Medline

Brand MD, Evans SM, Mendes-Mourão J, Chappell JB (1973) Fluorocitrate inhibition of aconitate hydratase and the tricarboxylate carrier of rat liver mitochondria. Biochem J 134:217-224. CrossRef Medline

Chowen JA, de Fonseca FR, Alvarez E, Navarro M, García-Segura LM, Blázquez E (1999) Increased glucagon-like peptide-1 receptor expression in glia after mechanical lesion of the rat brain. Neuropeptides 33: 212-215. CrossRef Medline

Danbolt NC (2001) Glutamate uptake. Prog Neurobiol 65:1-105. CrossRef Medline

Dossat AM, Lilly N, Kay K, Williams DL (2011) Glucagon-like peptide 1 receptors in nucleus accumbens affect food intake. J Neurosci 31:1445314457. CrossRef Medline

Fonnum F, Johnsen A, Hassel B (1997) Use of fluorocitrate and fluoroacetate in the study of brain metabolism. Glia 21:106-113. CrossRef Medline

Grill HJ, Hayes MR (2009) The nucleus tractus solitarius: a portal for visceral afferent signal processing, energy status assessment and integration of their combined effects on food intake. Int J Obes (Lond) 33 [Suppl 1]:S11-S15. CrossRef Medline

Grill HJ, Hayes MR (2012) Hindbrain neurons as an essential hub in the neuroanatomically distributed control of energy balance. Cell Metab 16: 296-309. CrossRef Medline

Harasta AE, Power JM, von Jonquieres G, Karl T, Drucker DJ, Housley GD, Schneider M, Klugmann M (2015) Septal glucagon-like peptide 1 receptor expression determines suppression of cocaine-induced behavior. Neuropsychopharmacology 40:1969-1978. CrossRef Medline

Hassel B, Paulsen RE, Johnsen A, Fonnum F (1992) Selective inhibition of 
glial cell metabolism in vivo by fluorocitrate. Brain Res 576:120-124. CrossRef Medline

Hayes MR (2012) Neuronal and intracellular signaling pathways mediating GLP-1 energy balance and glycemic effects. Physiol Behav 106:413-416. CrossRef Medline

Hayes MR, Bradley L, Grill HJ (2009) Endogenous hindbrain glucagon-like peptide-1 receptor activation contributes to the control of food intake by mediating gastric satiation signaling. Endocrinology 150:2654-2659. CrossRef Medline

Hayes MR, De Jonghe BC, Kanoski SE (2010) Role of the glucagon-likepeptide-1 receptor in the control of energy balance. Physiol Behav 100: 503-510. CrossRef Medline

Hayes MR, Leichner TM, Zhao S, Lee GS, Chowansky A, Zimmer D, De Jonghe BC, Kanoski SE, Grill HJ, Bence KK (2011) Intracellular signals mediating the food intake-suppressive effects of hindbrain glucagon-like peptide-1 receptor activation. Cell Metab 13:320-330. CrossRef Medline

Hayes MR, Mietlicki-Baase EG, Kanoski SE, De Jonghe BC (2014) Incretins and amylin: neuroendocrine communication between the gut, pancreas, and brain in control of food intake and blood glucose. Annu Rev Nutr 34:237-260. CrossRef Medline

Hermann GE, Rogers RC (2008) TNFalpha: a trigger of autonomic dysfunction. Neuroscientist 14:53-67. CrossRef Medline

Hermann GE, Van Meter MJ, Rood JC, Rogers RC (2009) Proteinaseactivated receptors in the nucleus of the solitary tract: evidence for glialneural interactions in autonomic control of the stomach. J Neurosci 29: 9292-9300. CrossRef Medline

Hermann GE, Viard E, Rogers RC (2014) Hindbrain glucoprivation effects on gastric vagal reflex circuits and gastric motility in the rat are suppressed by the astrocyte inhibitor fluorocitrate. J Neurosci 34:10488-10496. CrossRef Medline

Hisadome K, Reimann F, Gribble FM, Trapp S (2011) CCK stimulation of GLP-1 neurons involves alphal-adrenoceptor-mediated increase in glutamatergic synaptic inputs. Diabetes 60:2701-2709. CrossRef Medline

Hsu TM, Hahn JD, Konanur VR, Lam A, Kanoski SE (2015) Hippocampal GLP-1 receptors influence food intake, meal size, and effort-based responding for food through volume transmission. Neuropsychopharmacology 40:327-337. CrossRef Medline

Iwai T, Ito S, Tanimitsu K, Udagawa S, Oka J (2006) Glucagon-like peptide-1 inhibits LPS-induced IL-1beta production in cultured rat astrocytes. Neurosci Res 55:352-360. CrossRef Medline

Kanoski SE, Fortin SM, Arnold M, Grill HJ, Hayes MR (2011) Peripheral and central GLP-1 receptor populations mediate the anorectic effects of peripherally administered GLP-1 receptor agonists, liraglutide and exendin-4. Endocrinology 152:3103-3112. CrossRef Medline

Kanoski SE, Rupprecht LE, Fortin SM, De Jonghe BC, Hayes MR (2012) The role of nausea in food intake and body weight suppression by peripheral GLP-1 receptor agonists, exendin-4 and liraglutide. Neuropharmacology 62:1916-1927. CrossRef Medline

Kobayashi K, Iwai T, Sasaki-Hamada S, Kamanaka G, Oka J (2013) Exendin (5-39), an antagonist of GLP-1 receptor, modulates synaptic transmission via glutamate uptake in the dentate gyrus. Brain Res 1505:1-10. CrossRef Medline

Koenig H (1969) Acute axonal dystrophy caused by fluorocitrate: the role of mitochondrial swelling. Science 164:310-312. CrossRef Medline

Lian XY, Stringer JL (2004) Energy failure in astrocytes increases the vulnerability of neurons to spreading depression. Eur J Neurosci 19:2446-2454. CrossRef Medline

Lim G, Wang S, Mao J (2005) cAMP and protein kinase A contribute to the downregulation of spinal glutamate transporters after chronic morphine. Neurosci Lett 376:9-13. CrossRef Medline

McDougal DH, Hermann GE, Rogers RC (2011) Vagal afferent stimulation activates astrocytes in the nucleus of the solitary tract via AMPA receptors: evidence of an atypical neural-glial interaction in the brainstem. J Neurosci 31:14037-14045. CrossRef Medline

McMahon LR, Wellman PJ (1998) PVN infusion of GLP-1-(7-36) amide suppresses feeding but does not induce aversion or alter locomotion in rats. Am J Physiol 274:R23-R29. Medline

Mietlicki-Baase EG, Ortinski PI, Rupprecht LE, Olivos DR, Alhadeff AL, Pierce RC, Hayes MR (2013) The food intake-suppressive effects of glucagon-like peptide-1 receptor signaling in the ventral tegmental area are mediated by AMPA/kainate receptors. Am J Physiol Endocrinol Metab 305:E1367-E1374. CrossRef Medline
Mietlicki-Baase EG, Ortinski PI, Reiner DJ, Sinon CG, McCutcheon JE, Pierce RC, Roitman MF, Hayes MR (2014) Glucagon-like peptide-1 receptor activation in the nucleus accumbens core suppresses feeding by increasing glutamatergic AMPA/kainate signaling. J Neurosci 34:6985-6992. CrossRef Medline

Moran TH (2006) Gut peptide signaling in the controls of food intake. Obesity (Silver Spring) 14 [Suppl 5]:250S-253S. CrossRef Medline

Paulsen RE, Contestabile A, Villani L, Fonnum F (1987) An in vivo model for studying function of brain tissue temporarily devoid of glial cell metabolism: the use of fluorocitrate. J Neurochem 48:1377-1385. CrossRef Medline

Perego C, Vanoni C, Bossi M, Massari S, Basudev H, Longhi R, Pietrini G (2000) The GLT-1 and GLAST glutamate transporters are expressed on morphologically distinct astrocytes and regulated by neuronal activity in primary hippocampal cocultures. J Neurochem 75:1076-1084. Medline

Peters RA (1957) Mechanism of the toxicity of the active constituent of Dichapetalum cymosum and related compounds. Adv Enzymol Relat Subj Biochem 18:113-159. Medline

Rajan S, Dickson LM, Mathew E, Orr CM, Ellenbroek JH, Philipson LH, Wicksteed B (2015) Chronic hyperglycemia downregulates GLP-1 receptor signaling in pancreatic beta-cells via protein kinase A. Mol Metab 4:265-276. CrossRef Medline

Ritter RC (2004) Gastrointestinal mechanisms of satiation for food. Physiol Behav 81:249-273. CrossRef Medline

Rogers RC, Nasse JS, Hermann GE (2006) Live-cell imaging methods for the study of vagal afferents within the nucleus of the solitary tract. J Neurosci Methods 150:47-58. CrossRef Medline

Rupprecht LE, Mietlicki-Baase EG, Zimmer DJ, McGrath LE, Olivos DR, Hayes MR (2013) Hindbrain GLP-1 receptor-mediated suppression of food intake requires a PI3K-dependent decrease in phosphorylation of membrane-bound Akt. Am J Physiol Endocrinol Metab 305:E751-E759. CrossRef Medline

Sandoval DA, Bagnol D, Woods SC, D’Alessio DA, Seeley RJ (2008) Arcuate glucagon-like peptide 1 receptors regulate glucose homeostasis but not food intake. Diabetes 57:2046-2054. CrossRef Medline

Schepp W, Schmidtler J, Riedel T, Dehne K, Schusdziarra V, Holst JJ, Eng J, Raufman JP, Classen M (1994) Exendin-4 and exendin-(9-39)NH2: agonist and antagonist, respectively, at the rat parietal cell receptor for glucagonlike peptide-1-(7-36)NH2. Eur J Pharmacol 269:183-191. CrossRef Medline

Scofield MD, Kalivas PW (2014) Astrocytic dysfunction and addiction: consequences of impaired glutamate homeostasis. Neuroscientist 20: 610-622. CrossRef Medline

Secher A, Jelsing J, Baquero AF, Hecksher-Sørensen J, Cowley MA, Dalbøge LS, Hansen G, Grove KL, Pyke C, Raun K, Schäffer L, Tang-Christensen M, Verma S, Witgen BM, Vrang N, Bjerre Knudsen L (2014) The arcuate nucleus mediates GLP-1 receptor agonist liraglutide-dependent weight loss. J Clin Invest 124:4473-4488. CrossRef Medline

Shirazi R, Palsdottir V, Collander J, Anesten F, Vogel H, Langlet F, Jaschke A, Schürmann A, Prévot V, Shao R, Jansson JO, Skibicka KP (2013) Glucagon-like peptide 1 receptor induced suppression of food intake, and body weight is mediated by central IL-1 and IL-6. Proc Natl Acad Sci U S A 110:16199-16204. CrossRef Medline

Sisley S, Gutierrez-Aguilar R, Scott M, D'Alessio DA, Sandoval DA, Seeley RJ (2014) Neuronal GLP1R mediates liraglutide's anorectic but not glucose-lowering effect. J Clin Invest 124:2456-2463. CrossRef Medline

Takahashi JL, Giuliani F, Power C, Imai Y, Yong VW (2003) Interleukin1beta promotes oligodendrocyte death through glutamate excitotoxicity. Ann Neurol 53:588-595. CrossRef Medline

Tella SH, Rendell MS (2015) Glucagon-like polypeptide agonists in type 2 diabetes mellitus: efficacy and tolerability, a balance. Ther Adv Endocrinol Metab 6:109-134. CrossRef Medline

Vance KM, Rogers RC, Hermann GE (2015) PAR1-activated astrocytes in the nucleus of the solitary tract stimulate adjacent neurons via NMDA receptors. J Neurosci 35:776-785. CrossRef Medline

Willoughby JO, Mackenzie L, Broberg M, Thoren AE, Medvedev A, Sims NR, Nilsson M (2003) Fluorocitrate-mediated astroglial dysfunction causes seizures. J Neurosci Res 74:160-166. CrossRef Medline

Yang L, Qi Y, Yang Y (2015) Astrocytes control food intake by inhibiting AGRP neuron activity via adenosine A1 receptors. Cell Rep 11:798-807. CrossRef Medline

Zheng H, Stornetta RL, Agassandian K, Rinaman L (2015) Glutamatergic phenotype of glucagon-like peptide 1 neurons in the caudal nucleus of the solitary tract in rats. Brain Struct Funct 220:3011-3022. CrossRef Medline 